preschool children) did not obtain results consistent with the Hullian predictions. They both found tendencies to repeat following a repetition and to alternate following an alternation. Thus, as far as the situations are comparable, the contrasting findings suggest both a developmental and comparative change in sequential responding (as well as in changes in behavior across TB). The developmental change is probably similar to changes in two-choice response strategies which occur with age when both responses are reinforced (e.g., Jeffrey \& Cohen, 1965).

\section{REFERENCES}

CROLL, W. L. Children's response alternation as a function of stimulus duration, intertrial interval, and trials. Psychonomic Science, 1966, 6, 247-248.

DEMBER, W. N., \& FOWLER, H. Spontaneous alternation behavior. Psychological Bulletin, $1958,55,412-428$.

GLANZER, M. Stimulus satiation: An explanation of spontaneous al ternation and related phenomena. Psychological Review, 1953, 60, 257.268.

HOLMAN, E. W. Tests for spontaneous altemation. Psychological Review, 1966, 73,427-436.

HULL, C. L. Principles of behovior. New York: Appleton-Century-Crofts, 1943.

IWAHARA, S., \& SUGIMURA, T. Studies in spontaneous alternation in human subjects: Il. Effects of stimulus-intervals and responding times. Japanese Journal of Psychology, 1959, 30,42-47.

JEFFREY, W. E., \& COHEN, L. B. Response tendencies of children in a two-choice situation. Journal of Experimental Child Psychology, 1965, 2, 248-254.

MANLEY, S., \& MILLER, F. D. Factors affecting children's alternation and choice behaviors. Psychonomic Science, 1968, 13, 65-66.

RABINOWITZ, F. M. Stimulus alternation and response repetition behavior of children. Unpublished doctoral dissertation, University of Iowa, 1965.

\section{NOTES}

1. The present experiment is one of a series of experiments included in the writer's doctoral dissertation. Gordon N. Cantor and Raymond H. Hohle of the University of Iowa, Institute of Child Behavior and Development, served as thesis co-chairmen. Their thoughtful advice and assistance throughout the course of the investigation was sincerely appreciated. The preparation of this manuscript was supported by Public Health Service Research Grant MH 12157-01 from the National Institute of Mental Health.

2. The cooperation of Ira J. Semler (Director of Research, Cedar Rapids Community School District, Cedar Rapids, Lowa), and Marlin Berg, Anthony Deeb, and Don Stonebraker (principals of various schools in the Cedar Rapids Community School District) is gratefully acknowledged.

\title{
Presentation time and the intuitive estimation of means
}

\section{P. M. J. BULGER, D. R. HILES, and G. LOWE, University of Hull, England}

Subjects were required to make intuitive estimates of the means of samples of $10 \mathrm{or}$ 20 numbers presented in visual arrays. In Experiment 1 presentation times were varied together with sample size in order to keep the information processing rate constant. In Experiment 2 sample size was kept constant as presentation time varied. Accuracy of Ss' estimates decreased when either informational load or rate increased.

In almost all studies of intuitive statistical judgments, the performance of Ss has been remarkably accurate, and comparable to that of relevant formal statistical procedures involving a good deal of computation. Beach \& Swenson (1966), for example, investi- gated the intuitive estimation of the means of number distributions which were either skewed or symmetric, and had high, medium, or low variance. Accuracy was found to be extremely high, but decreased somewhat as the size of the samples and their variance increased. Estimates of the mean obtained by Beach and Swenson were not significantly affected by the different types of instruction given to the three groups of Ss involved. The use of different strategies may, however, be a complicating factor, and similar to that in Spencer's studies $(1961,1963)$, where about half the $\mathrm{Ss}^{\circ}$ estimates appeared to be of medians or midranges.

A further difficulty arising from previous studies concerns the length of presentation times. In Spencer's experiments, samples of 10 and 20 numbers were each presented for
$10 \mathrm{sec}$, and Beach and Swenson used lists of three, five, or seven numbers with a presentation time of $7 \mathrm{sec}$. Under these conditions, it is doubtful whether Ss are actually making intuitive judgments, since a substantial amount of "deliberate" calculation is possible within these time intervals. Moreover, the observed difficulty that Ss have in assimilating information on the lists as the number of numbers increases may be a direct function of the information processing rate, and not sample size per se.

In the present investigation, presentation times were considerably reduced in order to decrease the opportunities for deliberate calculation, and hence ensure that Ss' estimates were based on mainly "intuitive" judgments. Furthermore, presentation times varied according to sample size, so that information processing rate was held constant.

\section{EXPERIMENT 1}

The first experiment was concerned with the replication of previous findings regarding the effects of sample size and variance on the intuitive estimation of sample means, with controlled presentation times.

\section{Apparatus}

Numbers (integers) between 0 and 20 were listed randomly in columns of five on slides which were back projected onto a $30 \times 30 \mathrm{in}$. screen. There were two array (sample) sizes with either 10 or 20 numbers from symmetrical distributions. For each array size, there were eight slides having the same mean (10) with four different variances $(66,36,18$, or 6$)$, and 10 slides with the same variance (6.4) having different means $(5,6,7,8$, or 9$)$. A shutter mechanism was controlled by a variable timing device, which was set at $2 \mathrm{sec}$ for Array Size 10, and $4 \mathrm{sec}$ for Array Size 20.

\section{Subjects}

Six undergraduate psychology students (three male and three female) served as Ss. They all had an adequate concept of the arithmetic mean and were of the same, above-average, intelligence level.

\section{Procedure}

Subjects were told that they would be presented with an array of numbers for a short length of time, and were instructed to "intuitively" estimate the mean of the sample of numbers. They were advised not to add up the numbers or carry out direct computations, but, in any case, there was not sufficient time to do so. Five seconds were allowed between presentations for $\mathrm{Ss}$ to write down their estimates and to prepare for the next slide. There were 108 presentations altogether, with the 36 different slides presented three times each in random order.

\section{Results}

Accuracy of Ss' intuitive judgments was assessed in terms of the absolute and signed 
Table 1

Mean Signed Deviation (MSD) and Mean Absolute Deviation (MAD) of Ss' Estimates from True Means as a Function of Sample Mean and Array Size.

\begin{tabular}{llcccccc} 
& \multicolumn{7}{c}{ Sample Mean } \\
& $\begin{array}{llc}\text { Array } \\
\text { Size }\end{array}$ & 5 & 6 & 7 & 8 & 9 & Average \\
\hline \multirow{3}{*}{ MSD } & 10 & +.472 & +.527 & +.694 & +.388 & +.333 & +.483 \\
& 20 & +.888 & +.861 & +.777 & +.694 & +.777 & +.800 \\
& Average & +.680 & +.694 & +.735 & +.541 & +.555 & +.641 \\
\multirow{3}{*}{ MAD } & 10 & .750 & .889 & 1.083 & .861 & .889 & .895 \\
& 20 & 1.194 & .972 & .778 & .889 & .889 & .945 \\
& Average & .872 & .931 & .931 & .875 & .889 & .920 \\
\hline
\end{tabular}

Table 2

Mean Signed Deviation (MSD) and Mean Absolute Deviation (MAD) of Ss' Estimates as a Function of Sample Variance and Array Size.

\begin{tabular}{llllccc} 
& \multicolumn{5}{c}{ Sample Variance } \\
& $\begin{array}{llllll}\text { Array } \\
\text { Size }\end{array}$ & 66 & 36 & 18 & 6 & Average \\
\hline \multirow{3}{*}{ MSD } & 10 & +.277 & +.720 & +.305 & +.222 & +.382 \\
& 20 & +1.750 & +1.833 & +1.055 & +1.331 & \\
& Average & +1.013 & +1.276 & +.666 & +.638 & +.856 \\
\multirow{3}{*}{ MAD } & 10 & 1.330 & 1.467 & 1.330 & 1.200 & 1.111 \\
& 20 & 2.330 & 2.800 & 1.833 & 1.733 & 1.812 \\
& Average & 1.830 & 2.133 & 1.582 & 1.467 & 1.462 \\
\hline
\end{tabular}

deviations of their estimates from the true means. Analy ses of variance were carried out on these measures. The results are consistent with previous observations of accurate performance. The overall mean absolute deviation (MAD) was 1.191, and the overall mean signed deviation (MSD) was only +.749 . Tables 1 and 2 show the main effects of means, variance, and array size, averaged over the group of six Ss. Error scores for Array Size 10 were significantly less than those for Array Size $20(p<.01)$ in all cases, except for MAD values on samples with constant variance. Larger variances tended to decrease accuracy, although the overall effect of variance was not significant on either error score $(F=2.5, .10>p>.05)$. Accuracy was not significantly affected when means were taken as an independent variable $(F<1$, n.s.). Highly significant $S$ differences were found, however $(F>4.0$, $p<.01$ ), and examination of the interactions indicated that $\mathrm{S}$ differences were closely related to variance $(F=2.0$, $\mathrm{p}<.05$ ).

\section{EXPERIMENT 2}

The most significant result of the first experiment was the effect of array size, even though presentation time varied with array size so that information processing rate was held approximately constant. One possible explanation of this result could be that, with reduced times of presentation, the shorter presentation time may result in increased accuracy of Ss' intuitive judgments. The next experiment, then, designed to test this particular hypothesis, manipulated information processing rate, not by varying array size as in earlier studies, but by varying presentation time with array size held constant.

The results of the present experiments indicate that $S$ s were still remarkably accurate in estimating the mean of a sample of numbers when presentation times were considerably reduced, as compared with previous studies. A consistent effect of array size has been found and may be attributed to the increased information processing rate involved. This has been suggested in an earlier study (Lowe, 1968), concerned with
Table 3

Mean Signed Deviation (MSD) and Mean Absolute Deviation (MAD) of Ss' Estimates from True Means as a Function of Presentation Time. Array Size was Fixed at 20 Numbers.

\begin{tabular}{ccccc}
\hline \multicolumn{5}{c}{$\begin{array}{c}\text { Presentation } \\
\text { Time }\end{array}$} \\
& $2 \mathrm{sec}$ & $4 \mathrm{sec}$ & $\mathrm{F}$ & \multicolumn{1}{c}{ p } \\
\hline MSD & +.700 & +.481 & 4.94 & $<.05$ \\
MAD & .981 & .757 & 9.0 & $<.01$ \\
\hline
\end{tabular}

the intuitive estimation of means under conditions of simultaneous auditory and visual inputs. However, the significant array size effect in Experiment 1, where an attempt was made to keep information processing rate constant, suggests that the accuracy of intuitive judgments of this kind depends, to some extent, on information load as well as rate. Ss may be forced to use different perceptual and/or decision strategies whenever the visual input exceeds the normal span of "attention." For instance, it seems likely that arrays of 20 numbers will necessitate more active scanning on the part of the $\mathrm{O}$ than arrays of only 10 numbers. This could involve a difference between simultaneous and sequential processing strategies.

Another feature of the present study was the tendency shown by Ss to overestimate as revealed by the positive mean signed deviations. On this basis, the degree of overestimation was significantly increased by array size and information processing rate. In other words, when informational load and/or rate is increased, more weight is given to the larger numbers in a display sample.

A final point concerns the significant $S$ differences found in the present experiments. Spencer (1961) reported negligible differences between Ss (also a group of students), and suggested that averaging ability is therefore related to "general intellectual ability" rather than specific ability. The apparent discrepancy between the present findings and those of Spencer, however, might also be explained in terms of the different presentation times involved. The shorter presentation times in Experiments 1 and 2 allow a more sensitive measure to be taken of intuitive estimation, and, in view of the alternative strategies mentioned above, differences between Ss would be expected.

\section{REFERENCES}

BEACH, L. R., \& SWENSON, R. G. Intuitive estimation of means. Psychonomic Science, $1966,5,161-162$.

LOWE, G. Intuitive estimation of means with auditory and visual presentation. Perceptual \& Motor Skills, 1968, 27, 890 .

SPENCER, J. Estimating averages. Ergonomics, $1961,4,317-328$

SPENCER, J. A further study of estimating averages. Ergonomics, 1963, 6, 255-265. 